\title{
Effect of Lagrangian-phase Modelling on Charge Stratification and Spatial Distribution of Threshold Soot Index for Toluene Reference Fuel Surrogates
}

\author{
Valentina Pessina ${ }^{1 *}$, Massimo Borghi ${ }^{1}$ \\ ${ }^{1}$ Department of Engineering “Enzo Ferrari”, University of Modena and Reggio Emilia, Via Vivarelli \\ 10, Modena 41125, Italy
}

\begin{abstract}
Nowadays, soot emissions are one of the major concerns in Direct Injection Spark Ignition engines. Soot prediction models can be computationally expensive, especially when particle mass, number, and size distribution are to be forecast. While soot formation heavily depends on the chemical and physical characteristics of the fuel, the simulation of the exact composition of a real gasoline is computationally unfeasible. Thus, it is essential to find simplified yet representative pathways to reduce the computational cost of the simulations. On the one hand, the a-priori investigation of the factors influencing particulate onset can be a simplified approach to compare different solutions and strategies with much cheaper costs than the modelling of soot formation and oxidation mechanisms. On the other hand, the use of surrogate fuels is a practical approach to cope with the fuel chemical nature. Although they poorly mimic the evaporation properties of a real gasoline, Toluene Reference Fuels are broadly adopted to match combustion relevant properties of the real fuels. In this study, the spatial distribution of the Threshold Soot Index in the fluid domain is investigated for three surrogates characterized by an increasing content of toluene $(0 \mathrm{~mol} \%, 30 \mathrm{~mol} \%, 60 \mathrm{~mol} \%)$. The correlation between the sooting tendency and the fuel distribution in the combustion chamber before spark ignition time can provide useful preliminary indications, without spending the computational effort of the whole soot model multicycle resolution. In particular, two approaches for the lagrangian description of the injected fuel are investigated: a multicomponent approach and a single component one, this last driven by a high-fidelity lumped modelling of the surrogate properties for both liquid and vapor phase.
\end{abstract}

\section{Introduction}

Alternative fuels, innovative combustion processes and aftertreatment systems are the predominant research fields to further develop Internal Combustion Engines (ICEs) amid the propulsion system innovation process. While waiting for mass-market penetration of alternative mobility solutions such as BEVs and FCEVs [1][2], ICEs are still populating the

\footnotetext{
${ }^{* 1}$ Corresponding author: valentina.pessina@,unimore.it
} 
large majority of passenger cars, although in the form of hybrid powertrains [3]. Among the ICEs, Direct Injection Spark Ignition (DISI) units must meet challenging and strict targets for the emissions, including Particulate Matter (PM) and Particle Number (PN). The combustion system should be optimized to effectively curb soot emissions, which are largely influenced by the combustion process and by the chemical nature of the burnt fuel. As for commercial gasolines, carbon-atom rich fuels belonging to the aromatic hydrocarbon class [4] are more prone to generate soot, especially in fuel-rich mixture combustion, when the fuel pyrolysis process is triggered. Emissions in ICEs can be investigated with both experiments at the test bench and Computational Fluid Dynamics (CFD): accurate description of flow field [5], spray [6][7], mixing [8], combustion [9][10], knock [11][12], and emission formation [13] can be achieved with advanced models. The estimation of soot production during fuel oxidation via CFD tools can be achieved both employing detailed chemistry resolution [14] and a chemistry-tabulated approach [8] [15]. In both approaches, the chemical composition of the fuel is required as an input. To this aim, the simulation of the exact gasoline composition is impractical. The reason is twofold: on the one hand, the knowledge of the gasoline exact composition requires complex gas chromatography analyses; on the other hand, a reaction mechanism that encompasses all components may not be available. To tackle this problem, actual fuels are replaced by so-called fuel surrogates, which are mixtures of fewer well-known hydrocarbons; the composition depends on the properties of the reference fuel that are to be matched. Surrogates have been extensively adopted for several applications, from commercial gasolines [16] to jet fuels [5][6]. Although Toluene Reference Fuel (TRF) and Primary Reference Fuel (PRF) do not match the evaporation properties of the real gasolines, due to the absence of high-temperature normal boiling point components, such surrogates are widely adopted in DISI engine combustion simulations. Numerous examples of PRFs/TRFs can be found for soot formation and combustion investigation, both experimentally [19] and numerically [20][21][22]. TRF surrogates are widely adopted to match the combustion-relevant properties of a fuel, such as the Research Octane Number (RON), Motor Octane Number (MON), the stoichiometric airfuel ratio $\alpha_{\text {st }}$, and the sooting tendency [23] whenever the oxygenate content is almost negligible [24]. The sooting tendency of a fuel can be expressed by proper indices such as: the Smoke Point (SP) [25], the Threshold Soot Index (TSI) [23], the Yield Sooting Index (YSI) [26], or the Oxygen Extended Sooting Index (OESI) [27]. Once the surrogate is formulated, two approaches can be adopted for both spray and combustion modelling: one is the multicomponent approach, where each surrogate component is injected with its own properties, and the other is the lumped-single component approach, in which the surrogate is modelled as a single liquid with averaged properties, depending on the composition. Shedding light on the differences between the multicomponent approach and the lumpedsingle component approach in terms of charge stratification is crucial to the insight of sooting tendency, which is highly correlated to the cell-wise value of equivalence ratio. In this study, three surrogate blends are formulated, and their charge stratification and Threshold Sooting Index (TSI) spatial distribution are evaluated at spark time in the attempt to provide insight on the condition experienced by the flame front at the beginning of its propagation throughout the combustion chamber. More specifically, the three investigated blends are characterized by RON, MON, and $\alpha_{\text {st }}$ values very similar to those of a commercial gasoline, while the sooting tendency is characterized by largely different TSIs, which are increased by $\sim 10$ points from one surrogate to another by varying the toluene content. In this way, the TSI distribution in the combustion domain can be tested for a wide range of aromatic contents. The comparison between the two lagrangian phase modelling approaches, the multicomponent and the lumped-single component, is carried out with focus on two factors that significantly impact soot formation in DISI engines: charge stratification and sooting tendency. The prediction of the TSI field and its distribution can provide indications on the 
formation of local soot-prone areas within the combustion chamber, which can be addressed without the high computational burden of multicycle soot simulations. The effectiveness of a lumped fuel-modelling approach is critically investigated by evaluating the predictions of fuel and TSI distributions at spark time, to spot to what extent the lumped-single component approach is reliable and able to predict charge stratification and TSI distribution compared to a more refined, yet more expensive, multicomponent fuel modelling approach.

\section{Methodology}

\subsection{Surrogate fuel formulation}

Surrogate formulation is carried out by defining the reference fuel properties of interest, and then by selecting what types of hydrocarbons and compounds to be employed. In this study, the target properties are RON, MON, and $\alpha_{\text {st }}$, which describe the main flame propagation and ignition quality of the mixture, then the sooting tendency is also accounted for. In this study, TSI [23] is chosen as the representative index for the soot formation propensity quantification. The surrogate components are: $2,2,4$ trimethyl-pentane $\left(\mathrm{C}_{8} \mathrm{H}_{18}\right)$ as representative of the iso-paraffins, n-heptane $\left(\mathrm{C}_{7} \mathrm{H}_{16}\right)$ for n-paraffins, and toluene $\left(\mathrm{C}_{6} \mathrm{H}_{5} \mathrm{CH}_{3}\right)$ for aromatics. Surrogate compositions are obtained by actively targeting RON, MON, and $\alpha_{\text {st }}$ of a commercial gasoline [16], and by varying the toluene content to get stark differences in TSI between the three surrogates. Although the aromatic content of commercial gasoline is limited to below $30-35 \mathrm{vol} \%$ [16], it was increased up to $60 \%$ to explore the robustness of the lumped-single component approach in predicting TSI distribution. The surrogate composition is obtained by solving three equations representing the constraints of: total mole fraction equal to unity, RON and MON target modelled with a linear by mole mixing rule. The final composition of each surrogate is reported for toluene, n-heptane, iso-octane mol\% content respectively: 0-5.00-95.00 for PRF, 30.30-11.06 -58.64 for TRF30 and 60.61-17.1222.27 for TRF60. The other relevant properties of the surrogates, such as the carbon (C) or hydrogen $(\mathrm{H})$ atoms, liquid density $\left(\rho_{\mathrm{l}}\right)$ at $298 \mathrm{~K}$, Molecular Weight $(M W)$, Lower Heating Value $(L H V)$, and the Normal Boiling Temperature $\left(T_{\mathrm{b}}\right)$ are reported in Table 1.

Table 1. Properties of the three surrogate blends.

\begin{tabular}{ccccccccccc}
\hline Name & $\begin{array}{c}\mathbf{C} \\
{[-]}\end{array}$ & $\begin{array}{c}\mathbf{H} \\
{[-]}\end{array}$ & $\begin{array}{c}\boldsymbol{\alpha}_{\text {st }} \\
{[-]}\end{array}$ & $\begin{array}{c}\boldsymbol{M} \boldsymbol{W} \\
{[\mathrm{g} / \mathrm{mol}]}\end{array}$ & $\begin{array}{c}\boldsymbol{L H} \boldsymbol{V} \\
{[\mathrm{MJ} / \mathrm{kg}]}\end{array}$ & $\begin{array}{c}\boldsymbol{\rho}_{\mathbf{1}} \\
{\left[\mathrm{kg} / \mathrm{m}^{3}\right]}\end{array}$ & $\begin{array}{c}\boldsymbol{R O N} \\
{[-]}\end{array}$ & $\begin{array}{c}\boldsymbol{M O N} \\
{[-]}\end{array}$ & $\begin{array}{c}\boldsymbol{T S I} \\
{[-]}\end{array}$ & $\begin{array}{c}\boldsymbol{T}_{\mathbf{b}} \\
{[\mathrm{K}]}\end{array}$ \\
\hline PRF & 7.95 & 17.90 & 15.05 & 113.53 & 40.76407 & 689.70 & 95.00 & 95.00 & 6.50 & 372.3 \\
TRF30 & 7.59 & 14.75 & 14.63 & 105.99 & 41.98399 & 728.50 & 95.00 & 90.00 & 17.56 & 375.7 \\
TRF60 & 7.22 & 11.60 & 14.14 & 98.44 & 43.39128 & 779.04 & 95.00 & 85.00 & 28.62 & 379.1 \\
\hline
\end{tabular}

\subsection{D-CFD simulation general setup}

The surrogates are tested in a single-cylinder naturally aspirated engine [8], operated at 2000 rpm at Wide Open Throttle (WOT); the engine runs with a compression ratio of 10:1 and at average stoichiometric conditions with a nominal injected mass of $28 \mathrm{mg}$. The Start of Injection is labeled as SOI 300, since the fuel is injected 300 degrees before Top Dead Center firing (bTDC) directly in the combustion chamber with a 6-hole injector, positioned on the symmetry plane. Given the geometric symmetry and the adopted RANS modelling approach, which is here preferred to other more refined alternatives [28][29][30] to reduce the computational cost of the analyses, it is possible to simulate half combustion chamber, thus reducing the computational cost. The mesh has a minimum number of cells of $\sim 112^{`} 000$ (at 
TDC) and a maximum number of cells of $\sim 290000$ (at BDC). For turbulence modelling, a $\mathrm{k}-\varepsilon \mathrm{RNG}$ is adopted given the successful application in similar studies [31][32]. Droplets are initialized following the approach proposed in [33][34][35] whereas the spray break-up is modelled with Reitz-Diwakar's [36] model and the droplet-wall interaction with Senda's model [37]. Heat transfer is modeled using a recently improved version of the GruMoUnimore heat transfer model [38][39][40], which has proven to be successful in a wide range of engine applications [41].

\subsection{Multicomponent approach for lagrangian phase}

The multicomponent approach allows a high-fidelity description of each component of the surrogate fuel. Of particular interest for charge stratification is fuel evaporation, which depends on the equilibrium at the liquid-vapor interface; this in turn can be described using a simple Raoult's law or a more sophisticated description, as the one provided by the UNIQUAC Functional-group Activity Coefficients approach (UNIFAC) [42]. The latter relies on the use of activity coefficients $\gamma_{i}$ to provide a description of the partial pressure of each component $i$ at the liquid-vapor interface, and the properties of each fuel molecule are calculated as the sum of each functional contribution. The activity coefficients $\gamma_{i}$ are based on two types of contributions: one is influenced by the size of the molecule, and the other by the molecular interactions. The partial pressure of each component at the liquid-vapor interface $p_{\mathrm{vi}, \mathrm{s}}$ is reckoned with Equation 1 for Raoult's law, and with Equation 2 for the UNIFAC model: $x_{\mathrm{i}}$ is the mole fraction, $p_{\mathrm{vi}, \mathrm{s}}^{0}$ is the saturation pressure of the $i$ th component in the liquid mixture.

$$
p_{\mathrm{vi}, \mathrm{s}}=x_{\mathrm{i}} p_{\mathrm{vi}, \mathrm{s}}^{0} \quad \text { Eq. (1) } \quad p_{\mathrm{vi}, \mathrm{s}}=\gamma_{\mathrm{i}} x_{\mathrm{i}} p_{\mathrm{vi}, \mathrm{s}}^{0} \quad \text { Eq. (2) }
$$

Since activity coefficients account for the type of molecules and their interactions during the evaporation, the UNIFAC model is more reliable than the Raoult's law for applications involving surrogates, especially when different molecular structures are involved (e.g., the oxygenated compounds like ethanol for e-fuel surrogates).

\subsection{Single-component approach for lagrangian phase}

An alternative strategy to the multicomponent description, is the lumping of the individual fuel components into a single representative liquid [43][44]. In this case, the properties are calculated from those of each hydrocarbon using mixing rules. To establish how effective the lumped-single component strategy is in terms of evaporation, charge stratification, and TSI spatial distribution prediction, it is necessary to derive a high-fidelity single component for each blend. In this study, for each one of the three surrogates, a temperature-dependent description of both liquid and gas phase properties is provided. The general method that is applied is: the properties are calculated with mixing rules that weight each component property based on its specific proportion in the composition. The mixing rules to compute the mean properties of mixtures are retrieved from literature. For the majority of the properties, a linear mixing rule, historically developed by Kay et al. and widely adopted for hydrocarbon mixtures [45], is exploited: $F_{\text {mix }}=\sum_{i} \theta_{i} F_{i}$ where $F_{i}$ is the generic property, $\theta_{i}$ is the mole/mass/volume fraction of the component, subscript $i$ and mix stand for $i$ th component and mixture respectively. The types of mixing rule used to calculate the properties of each surrogate are summarized in Figure 1. As for the gaseous phase, the NASA polynomials of the lumped-single components are calculated using a mole-fraction linear mixing rule and the results (Figure 2) provide a description of the thermal properties of the vapor phase. 


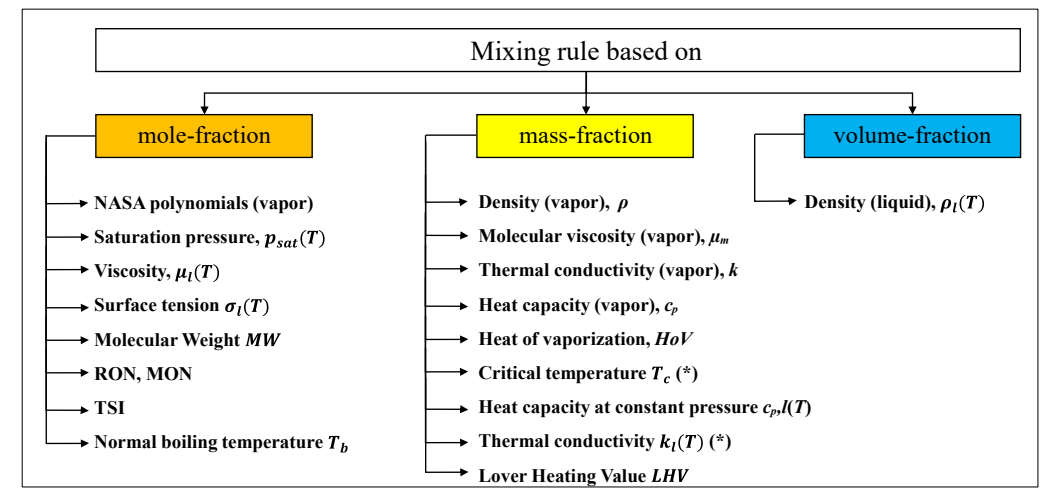

Figure 1. Schematic representation of the mixing rules adopted to calculate surrogate properties.

\begin{tabular}{|c|c|c|c|c|}
\hline \multicolumn{4}{|c|}{ NASA Polynomials -200-1000 K } & \multirow{2}{*}{$\frac{c_{p}}{\mathrm{R}}=\mathrm{a}_{0}+\mathrm{a}_{1} \cdot T+\mathrm{a}_{2} \cdot T^{2}+\mathrm{a}_{3} \cdot T^{3}+\mathrm{a}_{4} \cdot T^{4}$} \\
\hline & PRF & TRF30 & TRF60 & \\
\hline a0 & 1.332619 & 2.200341 & 3.068144 & \\
\hline a1 & 0.069127 & 0.048311 & 0.027490 & $a_{4} \cdot \frac{T^{4}}{5}$ \\
\hline a2 & $2.6717 \mathrm{E}-05$ & $5.7939 \mathrm{E}-05$ & $8.9168 \mathrm{E}-05$ & \\
\hline a3 & $-7.8379 \mathrm{E}-08$ & $-1.0846 \mathrm{E}-07$ & $-1.3855 \mathrm{E}-07$ & $T^{2}$ \\
\hline a4 & $3.5479 \mathrm{E}-11$ & $4.6703 \mathrm{E}-11$ & $5.7930 \mathrm{E}-11$ & $+\mathrm{a}_{2} \cdot \frac{1}{2}+\mathrm{a}_{3} \cdot \frac{T}{3}$ \\
\hline$a 5$ & $-3.0292 \mathrm{E}+04$ & $-1.9560 \mathrm{E}+04$ & $-8.8872 E+03$ & $T^{4}$ \\
\hline$a 6$ & 22.148059 & 18.552585 & 14.956724 & \\
\hline
\end{tabular}

\begin{tabular}{|r|rrr|}
\hline \multicolumn{4}{|c|}{ NASA Polynomials 1000-6000 K } \\
\hline & \multicolumn{1}{|c|}{ PRF } & \multicolumn{1}{c|}{ TRF30 } & \multicolumn{1}{c|}{ TRF60 } \\
\cline { 2 - 4 } $\mathbf{a}$ & 17.758120 & 16.513210 & 15.267830 \\
$\mathbf{a 1}$ & 0.050509 & 0.042044 & 0.033577 \\
$\mathbf{a} 2$ & $-1.6250 \mathrm{E}-05$ & $-1.3836 \mathrm{E}-05$ & $-1.1421 \mathrm{E}-05$ \\
$\mathbf{a 3}$ & $2.3943 \mathrm{E}-09$ & $2.0881 \mathrm{E}-09$ & $1.7819 \mathrm{E}-09$ \\
$\mathbf{a 4}$ & $-1.3370 \mathrm{E}-13$ & $-1.1903 \mathrm{E}-13$ & $-1.0437 \mathrm{E}-13$ \\
$\mathbf{a 5}$ & $-3.6157 \mathrm{E}+04$ & $-2.5000 \mathrm{E}+04$ & $-1.4078 \mathrm{E}+04$ \\
$\mathbf{a 6}$ & -69.234386 & -63.307586 & -57.378577 \\
\hline
\end{tabular}

Figure 2. NASA polynomial coefficients

The liquid phase properties $F_{j, m i x}$ are derived as monotone functions of temperature in the form of $F_{j, m i x}=\sum_{j=1}^{m} a_{j} T^{j}$, where $a_{j}$ are fitting coefficients. Then, all the properties are given as input to the CFD code via user coding. Each component property is retrieved from the NIST database [46] and then all the final surrogate properties are reckoned using a linear mixing rule (Figure 1), but the viscosity $\mu_{1}$ of the liquid phase. As reported by [45] [18], the computation of the viscosity of liquid hydrocarbon mixtures using a linear mixing rule may not be an effective approach: Kim et al. [18] successfully used the Grunberg-Nissan equation, whereas in [45] a nonlinear by mole mixing rule is suggested. This last is used in this study (Equation 3).

$$
\mu_{l, m i x}=\left(\sum_{i=1}^{\mathrm{N}} x_{i} \cdot \mu_{l, i}^{1 / 3}\right)^{3} \quad \text { Eq. (3) } \quad \mu_{l}=1000 \cdot \exp \left(\mathrm{A}+\frac{\mathrm{B}}{T}+\mathrm{C} \cdot \ln T+\mathrm{D} \cdot T^{\mathrm{E}}\right) \quad \text { Eq. (4) }
$$

The pure component viscosity is reckoned as a function of temperature in Equation 4, where A, B, C, D, E are tabulated constants [45] and the final value is in centipoise. The saturation pressure is a key property for phase transition: a linear by mole mixing rule [18] is employed to calculate the surrogate saturation pressure for the lumped approach. Each component saturation pressure values are retrieved from [46] a then the lumped-fuel saturation pressure is fitted to describe the vapor pressure in the form of an Antoine's Equation $\log _{10} p_{\text {sat }}(T)=\mathrm{A}-\mathrm{B} /(\mathrm{C}+T)$. The lumped-single component properties and their mathematical description is summarized in Figure 3, and they can be extended up to the critical temperature. 


\begin{tabular}{|c|c|c|c|c|c|c|c|c|c|}
\hline \multirow{4}{*}{$\begin{array}{c}\text { Saturation } \\
\text { Pressure in bar }\end{array}$} & \multicolumn{2}{|r|}{ PRF } & \multirow{2}{*}{\begin{tabular}{|l|} 
TRF30 \\
4.098 \\
\end{tabular}} & \multirow{2}{*}{$\begin{array}{c}\text { TRF60 } \\
4.133 \\
\end{array}$} & \multirow{4}{*}{$\begin{array}{l}\text { Density in } \\
\mathbf{k g} \cdot \mathbf{m}^{-3}\end{array}$} & \multicolumn{2}{|r|}{ PRF } & \multirow{2}{*}{$\begin{array}{c}\text { TRF30 } \\
-3.22379 \mathrm{E}-04\end{array}$} & \multirow{2}{*}{$\begin{array}{c}\text { TRF60 } \\
-2.18306 \mathrm{E}-04 \\
\end{array}$} \\
\hline & $\mathbf{A}$ & 4.070 & & & & a2 & $-1.94767 \mathrm{E}-04$ & & \\
\hline & B & 1328.648 & 1350.636 & 1371.314 & & a1 & $-7.36670 \mathrm{E}-01$ & $-6.74590 \mathrm{E}-01$ & $-7.67061 \mathrm{E}-01$ \\
\hline & $\mathrm{C}$ & -45.302 & -45.444 & -46.677 & & a0 & $9.16554 \mathrm{E}+02$ & $9.55212 \mathrm{E}+02$ & $1.02297 \mathrm{E}+03$ \\
\hline \multirow{4}{*}{$\begin{array}{c}\text { Thermal } \\
\text { Conductivity } \\
\text { in } \mathbf{W} \cdot \mathbf{m}^{-1} \cdot \mathbf{K}^{-1}\end{array}$} & & PRF & TRF30 & TRF60 & \multirow{5}{*}{$\begin{array}{c}\text { Surface } \\
\text { Tension in } \\
\mathbf{N} \cdot \mathbf{m}^{-1}\end{array}$} & & PRF & TRF30 & TRF60 \\
\hline & a1 & $-1.95955 \mathrm{E}-04$ & $-2.08100 \mathrm{E}-04$ & $-2.22107 \mathrm{E}-04$ & & & $\begin{array}{ll}3.53005 \mathrm{E}-10 \\
\end{array}$ & $5.84519 \mathrm{E}-11$ & $6.32000 \mathrm{E}-11$ \\
\hline & $\begin{array}{ll}\text { a0 } \\
\end{array}$ & $1.57438 \mathrm{E}-01$ & $1.72800 \mathrm{E}-01$ & $1.90529 \mathrm{E}-01$ & & & $\begin{array}{lr}2 & -2.71982 \mathrm{E}-07 \\
\end{array}$ & $2.99116 \mathrm{E}-09$ & $-2.41000 \mathrm{E}-09$ \\
\hline & & & & & & & $1-2.40590 \mathrm{E}-05$ & $-1.18424 \mathrm{E}-04$ & $-1.29000 \mathrm{E}-04$ \\
\hline \multirow{4}{*}{$\begin{array}{l}\text { Specific Heat in } \\
\mathbf{k J} \cdot \mathbf{k g}^{-1} \cdot \mathbf{K}^{-1}\end{array}$} & & PRF & TRF30 & TRF60 & & & $\begin{array}{ll}0 & 4.03819 \mathrm{E}-02 \\
\end{array}$ & $5.49025 \mathrm{E}-02$ & $6.14000 \mathrm{E}-02$ \\
\hline & a2 & $5.02716 \mathrm{E}-06$ & $6.31937 \mathrm{E}-06$ & $7.81002 \mathrm{E}-06$ & \multirow{7}{*}{$\begin{array}{l}\text { Viscosity in } \\
\mathrm{Pa} \cdot \mathrm{s}\end{array}$} & & PRF & TRF30 & TRF60 \\
\hline & a1 & $1.20721 \mathrm{E}-03$ & $8.46502 \mathrm{E}-05$ & $-1.21031 \mathrm{E}-03$ & & & $6 \quad 1.65708 \mathrm{E}-15$ & $3.86794 \mathrm{E}-15$ & $6.98688 \mathrm{E}-15$ \\
\hline & a0 & $1.28704 \mathrm{E}+00$ & $1.41311 \mathrm{E}+00$ & $1.55853 \mathrm{E}+00$ & & & $5-2.82060 \mathrm{E}-12$ & $-6.52697 \mathrm{E}-12$ & $-1.17413 \mathrm{E}-11$ \\
\hline \multirow{4}{*}{$\begin{array}{c}\text { Heat of } \\
\text { Vaporization } \\
\text { in } \mathrm{kJ} \cdot \mathrm{kg}^{-1}\end{array}$} & & PRF & TRF30 & $\overline{\text { TRF60 }}$ & & & $\begin{array}{cc}4 & 1.99809 \mathrm{E}-09 \\
3 & -7.54892 \mathrm{E}-07\end{array}$ & $\frac{4.57669 \mathrm{E}-09}{-1.70817 \mathrm{E}-06}$ & $\begin{array}{r}8.19308 \mathrm{E}-09 \\
-3.04028 \mathrm{E}-06\end{array}$ \\
\hline & & $-4.78263 \mathrm{E}-04$ & $-4.67531 \mathrm{E}-04$ & $-4.47756 \mathrm{E}-04$ & & & $2 \quad 1.60703 \mathrm{E}-04$ & $3.58293 \mathrm{E}-04$ & $6.33261 \mathrm{E}-04$ \\
\hline & a1 & $-1.98789 \mathrm{E}-01$ & $-2.39960 \mathrm{E}-01$ & $-2.91916 \mathrm{E}-01$ & & & $1-1.83257 \mathrm{E}-02$ & $-4.01115 \mathrm{E}-02$ & $-7.02819 \mathrm{E}-02$ \\
\hline & a0 & $4.11834 \mathrm{E}+02$ & $4.53160 \mathrm{E}+02$ & $5.02818 \mathrm{E}+02$ & & & ) $8.78537 \mathrm{E}-01$ & $1.87756 \mathrm{E}+00$ & $3.25325 \mathrm{E}+00$ \\
\hline
\end{tabular}

Figure 3. The A, B, C coefficients of the Antoine's equation and $a_{j}$ coefficients of the other liquid phase properties equations for the three surrogates.

\section{Results and discussion}

\subsection{Evaporation and charge stratification}

The simulation results are reported at spark time, which occurs 15 degrees bTDC, as a representative condition initially experienced by the flame propagation. The temporal evolution of the spray evaporation described as the percentage of evaporated fuel Evap.\% (xaxis) and the corresponding crank angle degree (y-axis) is summarized in Figure 4. The evaporation delay exhibited by the lumped approach stems from the approximation on the Heat of Vaporization and the partial pressure obtained using Raoult's law. However, differences in the evaporation rate partially influence charge stratification at spark time as suggested by the equivalence ratio scalar field Figure 5 and by the cell-wise occurrence frequency of equivalence ratio in Figure 6.
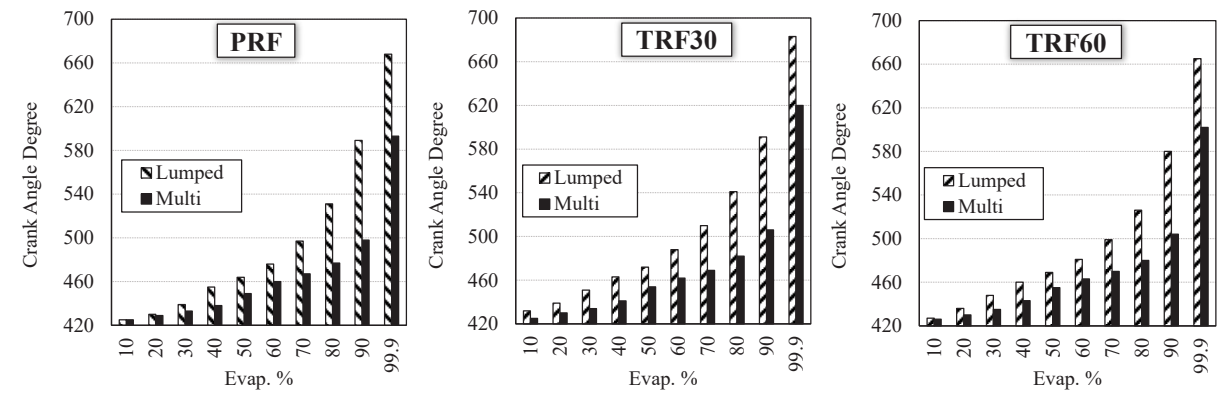

Figure 4. Evaporation description: multicomponent (full) and lumped-single component (striped) evaporation percentages on the $\mathrm{x}$-axis at the corresponding crank angle degree (CAD) on the y-axis.

It is also interesting to point out that the three surrogate fuels exhibit similar evaporation patterns since their $T_{\mathrm{b}}$ values are very close, as well as those of each component. 

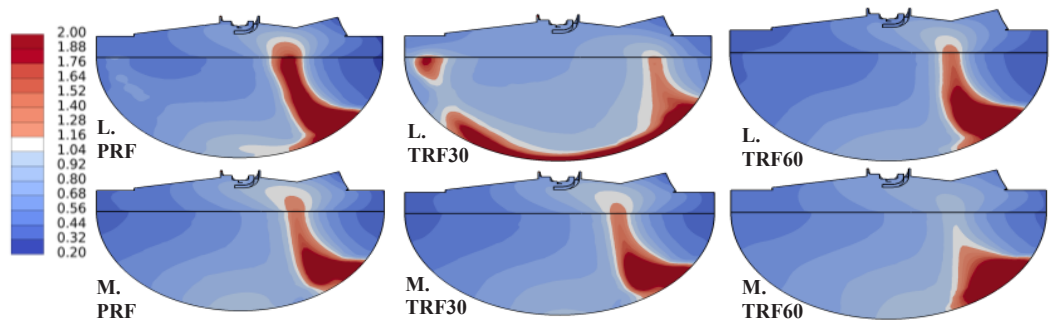

Figure 5. Equivalence ratio scalar field at spark time for lumped-single component (L.) and multicomponent (M.) at spark time.
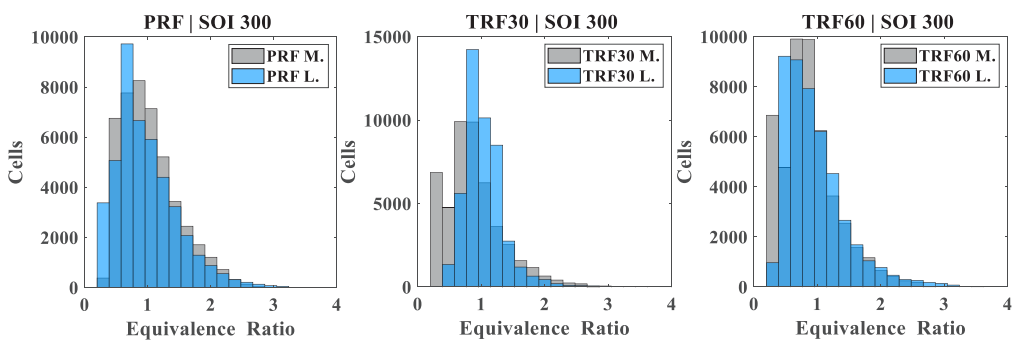

Figure 6. Histogram of cell-wise values of equivalence ratio for lumped-single component (L.) and multicomponent (M.) at spark time.

\subsection{Threshold Soot Index distribution}

Cell-wise TSI values are calculated via user coding as the surrogate TSI (Table 1) times the fuel mole fraction in the cell for the lumped-single component, whereas for the multicomponent approach a linear-by-mole mixing rule $\sum_{\mathrm{i}} x_{\mathrm{i}} \cdot \mathrm{TSI}_{\mathrm{i}}$ is applied using the cellwise mole fractions of each component $x_{\mathrm{i}}$ and the corresponding TSI value retrieved form [23]. The cell-wise value occurrence frequency in the domain is show in Figure 7: the histograms obtained by the multicomponent and by the lumped approach are superimposed to better spot the differences, which expectedly are very limited for the PRF, while tend to increase for the TRF30 and TRF60 blends.
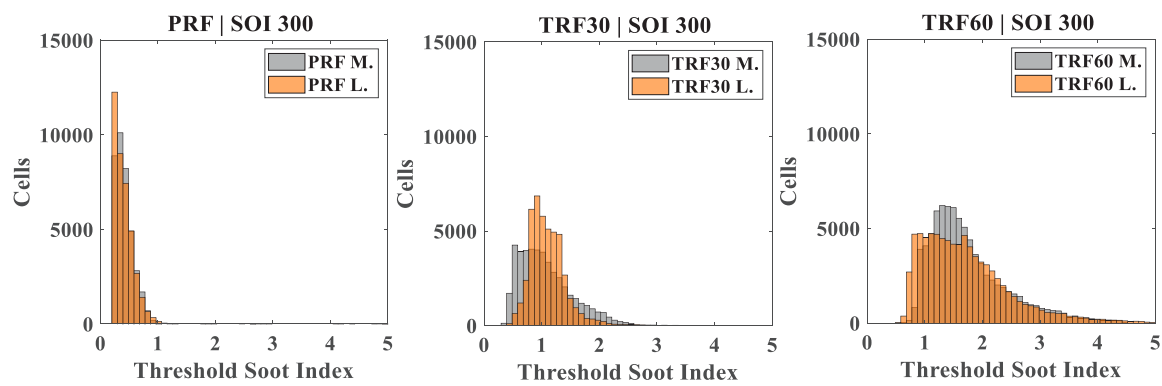

Figure 7. TSI cell-wise values histogram at spark time.

To quantify the TSI spatial distribution, the fluid domain is split in coaxial cylindrical sectors by varying the radius from $0 \mathrm{~mm}$ to $40 \mathrm{~mm}$ with a $10 \mathrm{~mm}$ stepping. To each one of the four sectors (Figure 8) a TSI average value is calculated as the algebraic average of all the TSI cell-wise values, belonging to a specific sector. A satisfying agreement between the two lagrangian phase modelling approaches is reached for the averaged TSI values, as shown in Figure 9. 


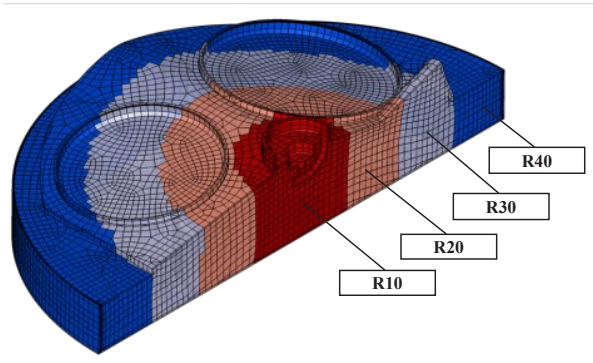

Figure 8. Schematic representation of the sectors of the fluid-dynamic domain.

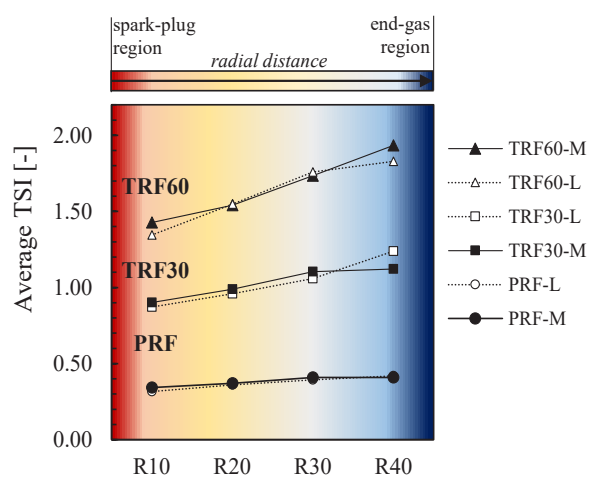

Figure 9. Cell-wise average TSI for each sector for multicomponent (full dot) and lumped-single component (empty dot) at spark time.

The values reported in Figure 9 provide the initial sooting tendency of the mixture, which the flame front will potentially experience during its propagation in the combustion chamber. However, local maxima of TSI also impact soot formation; it is therefore useful to spot cellwise differences obtained with the two approaches. In Figure 10, the TSI cell-wise distributions of high-TSI thresholds are reported as a complementary information to their averaged counterparts. A satisfying agreement for PRF is reached, whereas increasing variations of the TSI pattern can be spotted for the two TRFs.
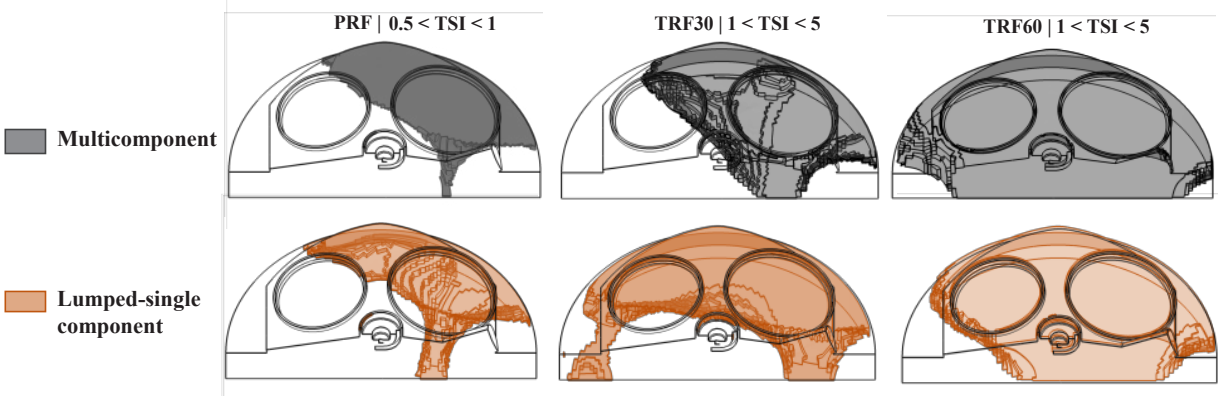

Figure 10. Local TSI distribution in the combustion chamber at spark time.

\section{Conclusions}

This study lays out a numerical comparison between a single-component approach and a multi-component approach to model mixture stratification in an DISI engine, with focus on the predicted sooting tendency. Firstly, a methodology to retrieve gas and liquid phase properties for the lumped approach is presented. Then the comparison is carried out focusing on equivalence ratio and TSI spatial distribution at spark time. The main aim is to investigate to what extent the results provided by the lumped approach differ from those obtainable using a more detailed multicomponent with UNIFAC modelling. Three surrogate fuels, characterized by an increasing toluene content, are investigated. The most relevant observations stemming from this study are: 
- For each surrogate, the lumped approach results in a slight evaporation delay when compared to the multicomponent one. This has a limited, yet observable, impact on the charge stratification for TRF30 and TRF60.

- For PRF, TRF30, and TRF60 a satisfying agreement of the radial TSI average value is observed between the two approaches.

- Spatial distribution of TSI peaks is very similar for the PRF surrogate, while increasing deviations between the single-component and the multi-component fuel representations are observed for the toluene-doped blends.

On a final remark, this approach is tested for hydrocarbon mixtures and TRF surrogates of alkanes and aromatics constituents. The mixing rule extension to other types of surrogates, in which compounds of a different chemical nature (e.g., alcohols) are blended with the PIONA (Paraffins, Iso-paraffins, Olefins, Naphthenes, Aromatics) constituents, must be evaluated, since non-linear blending effects can be observed (e.g., azeotropic behavior).

\section{References}

[1] A. d'Adamo, M. Riccardi, M. Borghi, and S. Fontanesi, "CFD Modelling of a Hydrogen/Air PEM Fuel Cell with a Serpentine Gas Distributor," Processes, vol. 9, no. 3, 2021, doi: 10.3390/pr9030564.

[2] A. D'Adamo, M. Riccardi, C. Locci, M. Romagnoli, and S. Fontanesi, "Numerical Simulation of a High Current Density PEM Fuel Cell," SAE International, Warrendale, PA, SAE Technical Paper 2020-24-0016, Sep. 2020. doi: 10.4271/2020-24-0016.

[3] V. Mangeruga, M. Giacopini, S. G. Barbieri, F. Berni, E. Mattarelli, and C. Rinaldini, "Design of a Hybrid Power Unit for Formula SAE Application: Packaging Optimization and Thermomechanical Design of the Electric Motor Case," SAE Int. J. Adv. Curr. Pract. Mobil., vol. 2, no. 2, Art. no. 2019-24-0197, Sep. 2019, doi: 10.4271/2019-24-0197.

[4] M. L. Botero, S. Mosbach, and M. Kraft, "Sooting tendency of paraffin components of diesel and gasoline in diffusion flames," Fuel, vol. 126, pp. 8-15, Jun. 2014, doi: 10.1016/j.fuel.2014.02.005.

[5] F. Rulli, S. Fontanesi, A. d'Adamo, and F. Berni, "A critical review of flow field analysis methods involving proper orthogonal decomposition and quadruple proper orthogonal decomposition for internal combustion engines," Int. J. Engine Res., vol. 22, no. 1, pp. 222-242, Jan. 2021, doi: 10.1177/1468087419836178.

[6] A. Cavicchi, L. Postrioti, F. Berni, S. Fontanesi, and R. Di Gioia, "Evaluation of hole-specific injection rate based on momentum flux measurement in GDI systems," Fuel, vol. 263, p. 116657, Mar. 2020, doi: 10.1016/j.fuel.2019.116657.

[7] A. Cavicchi, S. Sparacino, F. Berni, L. Postrioti, and S. Fontanesi, "Evaluation of the single jet flow rate for a multi-hole GDI nozzle", AIP Conference Proceedings, vol. 2191, p. 020043, Dec. 2019, doi: 10.1063/1.5138776.

[8] S. Fontanesi, M. Del Pecchia, V. Pessina, S. Sparacino, and S. Di Iorio, "Quantitative investigation on the impact of injection timing on soot formation in a GDI engine with a customized sectional method," Int. J. Engine Res., p. 146808742199395, Feb. 2021, doi: $10.1177 / 1468087421993955$.

[9] M. Del Pecchia and S. Fontanesi, "A methodology to formulate multicomponent fuel surrogates to model flame propagation and ignition delay," Fuel, vol. 279, p. 118337, Nov. 2020, doi: 10.1016/j.fuel.2020.118337.

[10] S. Breda et al., "Numerical Simulation of Gasoline and n-Butanol Combustion in an Optically Accessible Research Engine," SAE Int. J. Fuels Lubr., vol. 10, no. 1, Art. no. 2017-01-0546, Mar. 2017, doi: 10.4271/2017-01-0546.

[11] A. Rosetti, C. Iotti, A. Bedogni, G. Cantore, S. Fontanesi, and F. Berni, "CFD Analysis and Knock Prediction into Crevices of Piston to Liner Fireland of an High Performance ICE," SAE International, Warrendale, PA, SAE Technical Paper 2019-24-0006, Sep. 2019. doi: 10.4271/2019-24-0006.

[12] E. Severi, A. d'Adamo, F. Berni, S. Breda, M. Lugli, and E. Mattarelli, "Numerical Investigation on the Effects of Bore Reduction in a High Performance Turbocharged GDI 
Engine. 3D Investigation of Knock Tendency,” Energy Procedia, vol. 81, pp. 846-855, Dec. 2015, doi: 10.1016/j.egypro.2015.12.094.

[13] M. D. Pecchia et al., "Development of a Sectional Soot Model Based Methodology for the Prediction of Soot Engine-Out Emissions in GDI Units," SAE International, Warrendale, PA, SAE Technical Paper 2020-01-0239, Apr. 2020. doi: 10.4271/2020-01-0239.

[14] M. Mehl, J. Y. Chen, W. J. Pitz, S. M. Sarathy, and C. K. Westbrook, "An Approach for Formulating Surrogates for Gasoline with Application toward a Reduced Surrogate Mechanism for CFD Engine Modeling," Energy Fuels, vol. 25, no. 11, pp. 5215-5223, Nov. 2011, doi: 10.1021/ef201099y.

[15] C. Marchal, G. Moréac, C. Vovelle, C. Mounaïm-Rousselle, and F. Mauss, "Soot modelling in automotive engines," p. 7.

[16] S. M. Sarathy, A. Farooq, and G. T. Kalghatgi, "Recent progress in gasoline surrogate fuels," Prog. Energy Combust. Sci., vol. 65, pp. 67-108, Mar. 2018, doi: 10.1016/j.pecs.2017.09.004.

[17] D. Kim, J. Martz, A. Abdul-Nour, X. Yu, M. Jansons, and A. Violi, “A six-component surrogate for emulating the physical and chemical characteristics of conventional and alternative jet fuels and their blends," Combust. Flame, vol. 179, pp. 86-94, May 2017, doi: 10.1016/j.combustflame.2017.01.025.

[18] D. Kim, J. Martz, and A. Violi, "A surrogate for emulating the physical and chemical properties of conventional jet fuel," Combust. Flame, vol. 161, no. 6, pp. 1489-1498, Jun. 2014, doi: 10.1016/j.combustflame.2013.12.015.

[19] S. Liang, Z. Li, J. Gao, X. Ma, H. Xu, and S. Shuai, "PAHs and soot formation in laminar partially premixed co-flow flames fuelled by PRFs at elevated pressures," Combust. Flame, vol. 206, pp. 363-378, Aug. 2019, doi: 10.1016/j.combustflame.2019.05.007.

[20] J. Y. Tan, F. Bonatesta, H. K. Ng, and S. Gan, "Developments in computational fluid dynamics modelling of gasoline direct injection engine combustion and soot emission with chemical kinetic modelling," Appl. Therm. Eng., vol. 107, pp. 936-959, Aug. 2016, doi: 10.1016/j.applthermaleng.2016.07.024.

[21] S. Li et al., "Development of a phenomenological soot model integrated with a reduced TRFPAH mechanism for diesel engine application," Fuel, vol. 283, p. 118810, Jan. 2021, doi: 10.1016/j.fuel.2020.118810.

[22] Y. An, M. Jaasim, R. Vallinayagam, S. Vedharaj, H. G. Im, and Bengt. Johansson, "Numerical simulation of combustion and soot under partially premixed combustion of low-octane gasoline," Fuel, vol. 211, pp. 420-431, Jan. 2018, doi: 10.1016/j.fuel.2017.09.064.

[23] M. Del Pecchia, S. Fontanesi, J. Prager, C. Kralj, and H. Lehtiniemi, "A threshold soot indexbased fuel surrogate formulation methodology to mimic sooting tendency of real fuels in 3DCFD simulations," Appl. Energy, vol. 280, p. 115909, Dec. 2020, doi: 10.1016/j.apenergy.2020.115909.

[24] M. Del Pecchia, V. Pessina, F. Berni, A. d'Adamo, and S. Fontanesi, "Gasoline-ethanol blend formulation to mimic laminar flame speed and auto-ignition quality in automotive engines," Fuel, vol. 264, p. 116741, Mar. 2020, doi: 10.1016/j.fuel.2019.116741.

[25] R. J. Gill, D. B. Olson, and H. F. Calcote, "Correlations of Soot Formation in Turbojet Engines and in Laboratory Flames," in Volume 3: Coal, Biomass and Alternative Fuels; Combustion and Fuels; Oil and Gas Applications; Cycle Innovations, Amsterdam, The Netherlands, Jun. 1984, p. V003T06A018. doi: 10.1115/84-GT-108.

[26] M. J. Montgomery, D. D. Das, C. S. McEnally, and L. D. Pfefferle, "Analyzing the robustness of the yield sooting index as a measure of sooting tendency," Proc. Combust. Inst., vol. 37, no. 1, pp. 911-918, 2019, doi: 10.1016/j.proci.2018.06.105.

[27] E. J. Barrientos, "Group additivity in soot formation for the example of C-5 oxygenated hydrocarbon fuels," Combust. Flame, p. 15, 2013.

[28] F. Rulli, A. Barbato, S. Fontanesi, and A. d'Adamo, "Large eddy simulation analysis of the turbulent flow in an optically accessible internal combustion engine using the overset mesh technique," Int. J. Engine Res., vol. 22, no. 5, pp. 1440-1456, May 2021, doi: $10.1177 / 1468087419896469$.

[29] V. K. Krastev, A. d'Adamo, F. Berni, and S. Fontanesi, "Validation of a zonal hybrid URANS/LES turbulence modeling method for multi-cycle engine flow simulation," Int. J. Engine Res., vol. 21, no. 4, pp. 632-648, Jun. 2019, doi: 10.1177/1468087419851905. 
[30] A. d'Adamo, C. Iacovano, and S. Fontanesi, "Large-Eddy simulation of lean and ultra-lean combustion using advanced ignition modelling in a transparent combustion chamber engine," Appl. Energy, vol. 280, p. 115949, Dec. 2020, doi: 10.1016/j.apenergy.2020.115949.

[31] F. Berni, S. Breda, M. Lugli, and G. Cantore, "A Numerical Investigation on the Potentials of Water Injection to Increase Knock Resistance and Reduce Fuel Consumption in Highly Downsized GDI Engines," Energy Procedia, vol. 81, pp. 826-835, Dec. 2015, doi: 10.1016/j.egypro.2015.12.091.

[32] S. Fontanesi, G. Cicalese, A. d'Adamo, and G. Cantore, "A Methodology to Improve Knock Tendency Prediction in High Performance Engines," Energy Procedia, vol. 45, pp. 769-778, 2014, doi: 10.1016/j.egypro.2014.01.082.

[33] "Impact of different droplets size distribution on the morphology of GDI sprays: Application to multi-hole injectors: AIP Conference Proceedings: Vol 2191, No 1." https://aip.scitation.org/doi/abs/10.1063/1.5138872 (accessed May 27, 2021).

[34] Sparacino, Berni, d'Adamo, Krastev, Cavicchi, and Postrioti, "Impact of the Primary Break-Up Strategy on the Morphology of GDI Sprays in 3D-CFD Simulations of Multi-Hole Injectors," Energies, vol. 12, no. 15, p. 2890, Jul. 2019, doi: 10.3390/en12152890.

[35] S. Sparacino, F. Berni, M. Riccardi, A. Cavicchi, and L. Postrioti, "3D-CFD Simulation of a GDI Injector Under Standard and Flashing Conditions," E3S Web Conf., vol. 197, p. 06002, 2020, doi: 10.1051/e3sconf/202019706002.

[36] R. D. Reitz and R. Diwakar, "Effect of Drop Breakup on Fuel Sprays," Feb. 1986. doi: https://doi.org/10.4271/860469.

[37] J. Senda, T. Kanda, M. Al-Roub, P. V. Farrell, T. Fukami, and H. Fujimoto, "Modeling Spray Impingement Considering Fuel Film Formation on the Wall," SAE Trans., vol. 106, pp. 98-112, 1997.

[38] F. Berni and S. Fontanesi, "A 3D-CFD methodology to investigate boundary layers and assess the applicability of wall functions in actual industrial problems: A focus on in-cylinder simulations," Appl. Therm. Eng., vol. 174, p. 115320, Jun. 2020, doi: 10.1016/j.applthermaleng.2020.115320.

[39] S. Fontanesi, G. Cicalese, G. Cantore, and A. D'Adamo, "Integrated In-Cylinder/CHT Analysis for the Prediction of Abnormal Combustion Occurrence in Gasoline Engines," SAE Technical Paper, 2014-01-1151, 2014, doi.org/10.4271/2014-01-1151.

[40] F. Berni, G. Cicalese, S. Sparacino, and G. Cantore, "On the existence of universal wall functions in in-cylinder simulations using a low-Reynolds RANS turbulence model," AIP Conf. Proc., vol. 2191, no. 1, p. 020019, Dec. 2019, doi: 10.1063/1.5138752.

[41] F. Berni, G. Cicalese, M. Borghi, and S. Fontanesi, "Towards grid-independent 3D-CFD wallfunction-based heat transfer models for complex industrial flows with focus on in-cylinder simulations," Appl. Therm. Eng., vol. 190, p. 116838, May 2021, doi: 10.1016/j.applthermaleng.2021.116838.

[42] R. C. Reid, J. M. Prausnitz, and B. E. Poling, The properties of gases and liquids. United States: McGraw Hill Book Co.,New York, NY, 1987. [Online]. https://www.osti.gov/biblio/6504847

[43] S. Malaguti, S. Fontanesi, and E. Severi, "Numerical Analysis of GDI Engine Cold-Start at Low Ambient Temperatures," SAE International, Warrendale, PA, SAE Technical Paper 2010-012123, Oct. 2010. doi: 10.4271/2010-01-2123.

[44] S. Malaguti, G. Cantore, S. Fontanesi, R. Lupi, and A. Rosetti, "CFD Investigation of Wall Wetting in a GDI Engine under Low Temperature Cranking Operations," SAE International, Warrendale, PA, SAE Technical Paper 2009-01-0704, Apr. 2009. doi: 10.4271/2009-01-0704.

[45] M. R. Riazi, Characterization and properties of petroleum fractions. W. Conshohocken, PA: ASTM International, 2005.

[46] Peter Linstrom and William Mallard, "The NIST Chemistry WebBook: A Chemical Data Resource on the Internet," no. 46, 2001. 